\title{
ANALISIS PEMANFAATAN PELAYANAN KESEHATAN DI PUSKESMAS DEMPAR KECAMATAN NYUATAN KABUPATEN KUTAI BARAT
}

\author{
Deby Eunike Lestari'1), Iwan M. Ramdan²), Andi Anwar') \\ 1,2,3 Departemen Administrasi Kebijakan Kesehatan, Fakultas Kesehatan \\ Masyarakat Universitas Mulawarman, Samarinda, Kalimantan Timur, \\ Indonesia \\ Email: debyeunikelestari95@yahoo.com
}

\begin{abstract}
Low of visit number in Health service utilization is affected by many factors. Influencing faktors are health service user and service provider. This research aimes to know social structural factor, health belief and health assessment correlates wit health service utilization in Puskesmas Dempar. This quantitative research uses analytic survery with cross sectional approach that is done on August - September in 2018, sampling technique used a random sampling method with 299 respondents in the working area of the Dempar Health Center. Primary data collection methods (questionnaires and interviews). The statistical test used is the Chi Square test. Research result shows that on dependent variable $88.3 \%$ respondents utilized health service well, and after it is tested the correlation with independent variable is there were correlations between health assessment variable with health service utilization with significant value $(p=0,004)$, whereas variable there are no correlations between social structure $(p=0,497)$ and health belief $(p=0,844)$ toward health service usage in Puskesmas Dempar. It is suggested for Puskesmas Dempar to makes knowledge improvement and attitude change through counselling about disease along with health program socialization, health officer to approach society, also by improving service well.
\end{abstract}

Keywords $\quad$ : Belief, Assessment, Primary Health Care

\begin{abstract}
Abstrak
Kunjungan yang rendah dalam pemanfaatan pelayanan kesehatan dipengaruhi oleh banyak faktor. Faktor-faktor yang mempengaruhi yaitu pengguna pelayanan kesehatan dan penyedia layanan kesehatan. Penelitian ini bertujuan untuk mengetahui faktor struktur sosial, kepercayaan kesehatan dan penilaian kesehatan berhubungan dengan pemanfaatan pelayanan kesehatan di Puskesmas Dempar. Jenis penelitian kuantitatif menggunakan survey analitik dengan pendekatan secara cross sectional yang telah dilaksanakan pada bulan Agustus - September tahun 2018, teknik pengambilan sampel menggunakan cara random sampling dengan jumlah responden sebanyak 299 kepala keluarga yang berada di wilayah kerja Puskesmas Dempar. Metode pengambilan data secara primer (kuesioner dan wawancara). Uji statistik yang digunakan adalah uji Chi Square. Hasil penelitian menunjukkan bahwa pada variabel dependen $88.3 \%$ responden sudah memanfaatkan pelayanan kesehatan dengan baik, dan setelah di uji hubungan
\end{abstract}


dengan variabel independen yakni terdapat hubungan antara variabel penilaian kesehatan dengan pemanfaatan pelayanan kesehatan dengan nilai signifikansi yaitu $(p=0,004)$, sedangkan tidak terdapat hubungan dengan variabel struktur sosial $(p=0,497)$ dan kepercayaan kesehatan $(p=0,844)$ terhadap pemanfaatan pelayanan kesehatan di Puskesmas Dempar. Disarankan kepada Puskesmas untuk melakukan peningkatan pengetahuan dan sikap masyarakat melalui penyuluhan tentang penyakit serta sosialisasi program kesehatan, petugas kesehatan mendekatkan diri dengan masyarakat, serta meningkatkan mutu pelayanan yang baik.

Kata Kunci : Kepercayaan, Penilaian, Puskesmas

\section{PENDAHULUAN}

Derajat

kesehatan

masyarakat dapat dicapai dengan upaya pelayanan kesehatan primer yaitu Puskesmas. Berdasarkan Peraturan Menteri Kesehatan Nomor 75 Tahun 2014 tentang Puskesmas menyebutkan bahwa Puskesmas adalah fasilitas pelayanan kesehatan yang menyelenggarakan upaya kesehatan masyarakat dan upaya kesehatan perseorangan tingkat pertama, dengan lebih mengutamakan upaya promotif dan preventif, untuk mencapai derajat kesehatan masyarakat yang setinggi-tingginya di wilayah kerjanya (Permenkes, 2014).

Pada saat ini jumlah keberadaan Puskesmas di Indonesia adalah $\quad 9.825$ Puskesmas yang terbagi menjadi dua yaitu untuk rawat jalan 3.459 Puskesmas dan non rawat jalan 6.366 Puskesmas. Kemudian di provinsi Kalimantan Timur sendiri jumlah Puskesmas yang ada untuk rawat inap sebanyak 96 dan non rawat inap 83 total 179
Puskesmas, selanjutnya di Kabupaten kota khususnya Kabupaten kota Kutai Barat jumlah Puskesmas rawat inap 13 dan non rawat inap 5 total 18 Puskesmas (Data Puskesmas RI, 2017).

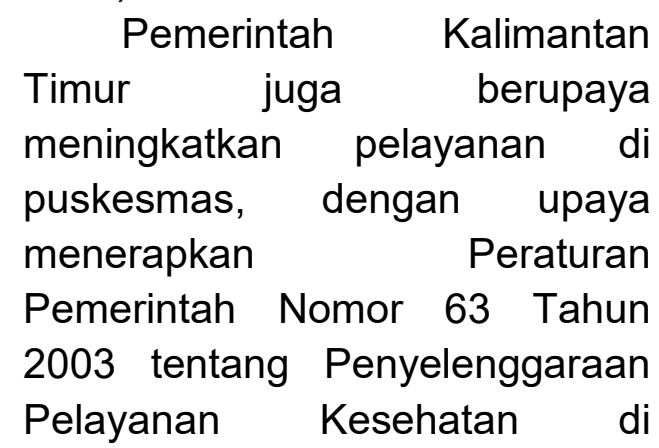
Puskesmas. Salah satu upaya yang dilakukan adalah dengan menyediakan fasilitas kesehatan terutama puskesmas yang mampu menjangkau segala lapisan masyarakat hingga daerah terpencil agar seluruh lapisan masyarakat mendapatkan pelayanan kesehatan yang optimal dalam mengatasi permasalahan kesehatan di masyarakat.

Pelaksanaan pemanfaatan puskesmas merupakan ujung tombak pelayanan kesehatan bagi masyarakat karena cukup 
efektif membantu masyarakat dalam pemberian pertolongan pertama dengan standar pelayanan yang murah seharusnya menjadikan puskesmas sebagai tempat pelayanan kesehatan utama bagi masyarakat, namun pada kenyataannya banyak masyarakat yang lebih memilih untuk melakukan pengobatan sendiri dengan membeli obat warung, menggunakan ramuan dan pengobatan tradisional ritual belian

Berdasarkan hasil studi pendahuluan, data yang didapatkan adalah tingkat pemanfaatan pelayanan kesehatan dalam 1 bulan tingkat kunjungan paling banyak dalam sehari adalah 25-30 pasien, untuk rata-rata perhari 10-16 pasien, dan paling rendah 3-5 orang pasien yang berkunjung untuk berobat dalam sehari. Berdasarkan data register kunjungan pasien yang datang ke pelayanan kesehatan pada tahun 2017 dengan total jumlah pasien yang berkunjung ke puskesmas Dempar dalam 1 tahun terakhir yaitu sebanyak 4.400 pasien yang datang untuk berobat ke puskesmas Dempar dan jika dihitung untuk rata-rata tingkat kunjungan pasien perbulan adalah 367 pasien (Register kunjungan pasien, 2017).
Pada penelitian Wahyuni (2012), hasil penelitian yang didapatkan terkait dengan pemanfaatan pelayanan kesehatan yaitu menyatakan bahwa gambaran masyarakat yang berkunjung ke Puskemas proporsi terbanyak pada usia 1755 dengan tingkat pendidikan rendah, kurangnya ketersediaan tenaga kerja, aksesbilitas, tingkat kemampuan dan kebutuhan masyarakat akan pelayanan kesehatan, serta persepsi sehat sakit di masyarakat dapat bepengaruh terhadap pemanfaatan pelayanan kesehatan.

Pada penelitian Wulandari (2016),tentang pemanfaatan pelayanan kesehatan di UPTD Puskesmas Langara menyatakan bahwa faktor-faktor yang mempengaruhi pemanfaatan pelayanan dipengaruhi oleh sarana atau alat puskesmas masih kurang, aksesbilitas, sikap petugas, kesadaran masyarakat, serta pendapatan masyarakat yang dominan masih rendah dikarenakan pekerjaan yang tidak menentu juga menjadi penyebab rendahnya minat masyarakat dalam memanfaatkan pelayanan kesehatan.

Selanjutnya pada penelitian yang dilakukan oleh Napirah (2016), melakukan wawancara dengan masyarakat yang tinggal diwilayah kerja Puskesmas 
Tambarana mengatakan bahwa kurangnya minat masyarakat untuk menggunakan pelayanan kesehatan ketika sakit adalah karena tidak memiliki cukup biaya untuk berobat dan bukan karena fasilitas atau bahkan pemberi pelayanan di Puskesmas Tambarana yang kurang baik.

Berdasarkan deskripsi diatas peneliti tertarik untuk melakukan penelitian terkait dengan analisis pemanfaatan pelayanan kesehatan di Puskesmas Dempar Kecamatan Nyuatan Kabupaten Kutai Barat

\section{METODE PENELITIAN}

Jenis penelitian yang digunakan adalah kuantitatif dengan pendekatan cross sectional. Penelitian ini dilaksanakan di 7 kampung wilayah kerja Puskesmas Dempar Kecamatan Nyuatan Kabupaten Kutai Barat, pada bulan Agustus - September tahun 2018. Jumlah sampel pada penelitian ini adalah sebanyak 299 responden dengan teknik sampling yang digunakan adalah Simpel Random Sampling. Variabel Independen dalam penelitian ini adalah struktur sosial, kepercayaan kesehatan, penilain kesehatan. Sedangkan untuk variabel dependen yaitu pemanfaatan pelayanan kesehatan.
Cara pengumpulan data yang digunakan terdiri dari metode kuesioner dan wawancara. Instrumen penelitian yang digunakan adalah lembar identitas umum pertanyaan pemanfaatan pelayanan kesehatan, struktur sosial, kepercayaan kesehatan dan penilaian kesehatan. Teknik analisis data yang digunakan terdiri dari analisis univariat dan analisis bivariat menggunakan uji contigency coefficient dengan nilai signifikansi $95 \%$ atau $\alpha=$ 0.05 .

\section{HASIL DAN PEMBAHASAN}

\section{A. Hasil}

Penelitian ini dilakukan pada 299 responden yang memenuhi kriteria inklusi dan ekslusi yang tersebar di 7 kampung di wilayah kerja Puskesmas Dempar Kecamatan Nyuatan Kabupaten Kutai Barat.

\section{B. Analisis Univariat}

Dilakukan analisis univariat untuk mengetahui distribusi frekuensi, presentase. Pada penelitian ini karakteristik responden dalam penelitian ini meliputi umur, jenis kelamin, pendidikan dan pekerjaan. Selanjutnya untuk mengetahui distribusi frekuensi variabel dependen (pemanfaatan pelayanan kesehatan) dan variabel independen yaitu (struktur sosial, kepercayaan kesehatan, penilaian kesehatan) 
disajikan dalam bentuk tabel distribusi frekuensi dan narasi.

Tabel 1. Kelompok Umur

\begin{tabular}{|c|c|c|}
\hline $\begin{array}{c}\text { Kelompok } \\
\text { Umur }\end{array}$ & $f$ & $(\%)$ \\
\hline $12-16$ tahun & 2 & 0,7 \\
\hline $17-25$ tahun & 48 & 16 \\
\hline $26-35$ tahun & 71 & 23,7 \\
\hline $36-45$ tahun & 83 & 27,8 \\
\hline $46-55$ tahun & 61 & 20,4 \\
\hline $56-65$ tahun & 39 & 11,4 \\
\hline
\end{tabular}

distribusi umur responden paling rendah dalam penelitian ini yaitu masa remaja awal ada $2(0,7 \%)$ responden, pada distribusi kelompok umur 12 - 16 tahun sedangkan umur tertinggi yaitu masa dewasa akhir sebanyak 83 $(27,8 \%)$ responden pada distribusi kelompok umur 36 - 45 tahun.

Tabel 2. Jenis Kelamin

\begin{tabular}{ccc}
\hline Jenis Kelamin & $\mathbf{f}$ & $\mathbf{( \% )}$ \\
\hline Laki-laki & 112 & 37.5 \\
Perempuan & 187 & 62.5 \\
\hline Tabel & 2 & menunjukan
\end{tabular}

frekuensi atau jumlah responden yang berjenis kelamin laki-laki sebanyak 112 orang atau $(37.5 \%)$ dan yang berjenis kelamin perempuan sebanyak 187 orang atau $(62.5 \%)$.
Tabel 3. Pendidikan

\begin{tabular}{ccc}
\hline Pendidikan & $\mathbf{f}$ & $\mathbf{( \% )}$ \\
\hline $\begin{array}{c}\text { Tidak } \\
\text { sekolah/tidak } \\
\text { tamat SD }\end{array}$ & 62 & 20.7 \\
Tamat SD & 99 & 33.1 \\
Tamat SMP & 58 & 19.4 \\
Tamat SMA/SMK & 66 & 22.1 \\
Akademi/Perguru & 14 & 4.7 \\
an Tinggi & & \\
\hline Tabel 3 & menunjukan \\
distribusi tingkat & pendidikan \\
responden terbanyak & adalah \\
tingkat pendidikan SD & ada 99 \\
(33.1\%) responden & sedangkan \\
paling sedikit yaitu & tingkat \\
pendidikan Akademi/Perguruan \\
Tinggi ada 14 (4.7\%) responden.
\end{tabular}

Tabel 4. Pekerjaan

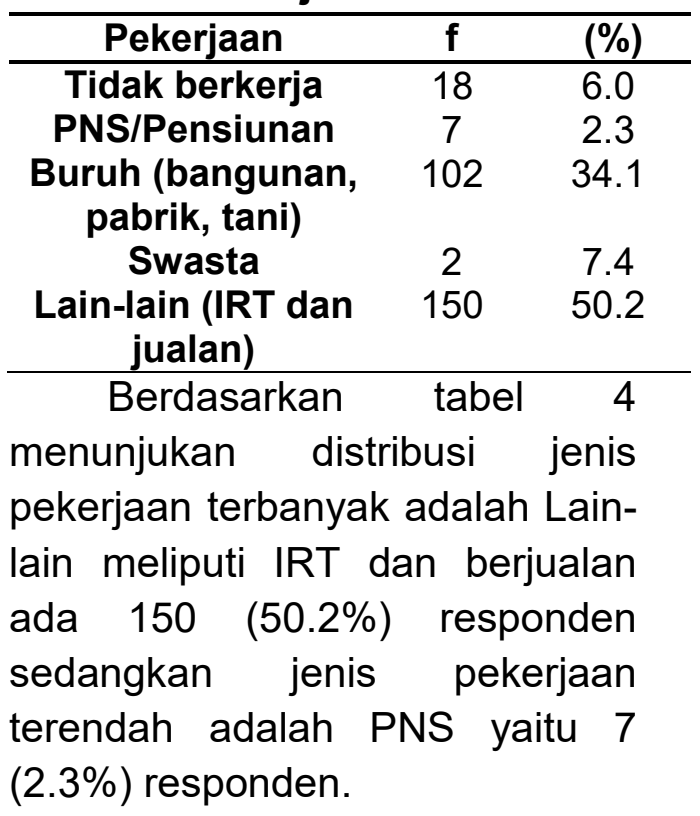


Tabel 5. Distribusi Variabel (42.8\%) memiliki tingkat penilaian Penelitian

\begin{tabular}{|c|c|c|c|}
\hline Variabel & $f$ & $(\%)$ & responden \\
\hline Dependen & & & buruk \\
\hline $\begin{array}{l}\text { Pemanfaan Pelayanan } \\
\text { Kesehatatn }\end{array}$ & & & \\
\hline - Memanfaatkan & 264 & 88.3 & C. Analisis Biva \\
\hline - Tidak memanfaatkan & 35 & 11.7 & Analisis \\
\hline $\begin{array}{l}\text { Independen } \\
\text { Struktur Sosial }\end{array}$ & & & mengetahui hubungan antara \\
\hline - Buruk & 172 & 57.5 & pemanfaatan \\
\hline - Baik & 127 & 42.5 & kesehatan denga \\
\hline Kepercayaan Kesehatan & & & kepercayaan kesehatan, dan \\
\hline $\begin{array}{l}\text { - Rendah } \\
\text { - Tinggi }\end{array}$ & $\begin{array}{l}107 \\
192\end{array}$ & $\begin{array}{l}30.0 \\
64.2\end{array}$ & penilaian kesehatan, dengan \\
\hline Penilaian Kesehatan & & & menggunakan bantuan software \\
\hline - Buruk & 171 & 57.2 & menggunakan uji contingency \\
\hline - Baik & 128 & 42.8 & il \\
\hline $\begin{array}{l}\text { Tabel } 5 \\
\text { distribusi } \\
\text { memanfaatkan }\end{array}$ & $\begin{array}{l}\text { ukan } \\
\text { nden }\end{array}$ & & $\begin{array}{l}\text { jika } p \text { value < alpha }(0,05) \text { ma } \\
\mathrm{H}_{0} \text { ditolak dan jika } p \text { value } \\
\text { alpha }(0.05) \text { maka } \mathrm{H}_{0} \text { diterima. }\end{array}$ \\
\hline
\end{tabular}

kesehatan di puskesmas Dempar selama tiga bulan terakhir ada $264 \quad(88.3 \%) \quad$ responden. Sedangkan ada $35 \quad(11.7 \%)$ responden yang tidak memanfaakan pelayanan kesehatan.

Selanjutnya untuk distribusi responden yang memiliki struktur sosial yang buruk ada sebanyak 172 (57.5\%). Sedangkan 127 $(42.5 \%)$ responden memiliki struktur sosial baik.

Kemudian untuk distribusi kepercayaan kesehatan ada sebanyak 107 (35.8\%) memiliki tingkat keyakinan yang rendah. Sedangkan ada 192 (64.2\%) memiliki tigkat kepercayaan yang tinggi.

Distribusi
terhadap penilaian kesehatan
didapatkan hasil sebanyak 128

\section{Hubungan Struktur Sosial dengan Pemanfaatan Pelayanan Kesehatan di Puskesmas Dempar}

Hasil dari hubungan antara struktur sosial dengan pemanfataan pelayanan kesehatan menggunakan uji contingency coefficient sebagai berikut :

Tabel 6. Hubungan Struktur Sosial dengan Pemanfaatan Pelayanan Kesehatan di Puskesmas Dempar

\begin{tabular}{ccc}
\hline Variabel & $\boldsymbol{P}$-value & $\boldsymbol{\alpha}$ \\
\hline $\begin{array}{c}\text { Struktur } \\
\text { Sosial }\end{array}$ & 0,497 & 0,05 \\
$\begin{array}{c}\text { Kepercayaa } \\
\text { n Kesehatan } \\
\begin{array}{c}\text { Penilaian } \\
\text { Kesehatan }\end{array}\end{array}$ & 0,844 & 0,004 \\
\hline
\end{tabular}


Berdasarkan hasil uji contingency coefficient hubungan struktur sosial dengan pemanfaatan pelayanan kesehatan nilai $p$ value dari varibel struktur sosial adalah 0,497 yang artinya nilai tersebut lebih besar dari pada nilai alpha yaitu 0,05 atau 0,497 >0,05 yang berarti tidak ada hubungan struktur sosial dengan pemanfaatan pelayanan kesehatan. Selanjutnya, variabel struktur sosial dengan pemanfaatan pelayanan kesehatan nilai $p$ value 0,844 yang artinya nilai tersebut lebih besar dari nilai alpha 0,05 atau $0,844>0,05$ berarti tidak ada hubungan kepercayaan kesehatan dengan pemanfaatan pelayanan kesehatan. Kemudian, variabel penilaian kesehatan dengan pemanfaatan pelayanan kesehatan nilai $p$ value 0,004 yang artinya nilai tersebut lebih kecil dari nilai alpha 0,05 atau $0,004<0,05$ berarti ada hubungan penilaian kesehatan dengan pemanfaatan pelayanan kesehatan.

\section{Pembahasan}

Berdasarkan pengolahan data dan analisis data, maka dilakukan pembahasan hasil penelitian sesuai dengan variabel yang diteliti.

\section{Gambaran Pemanfaatan Pelayanan Kesehatan di Puskesmas Dempar}

Pemanfaatan pelayanan puskesmas adalah penggunaan pelayanan yang telah diterima, atau pemberi pelayanan kesehatan. Sedangkan pelayanan kesehatan sendiri adalah setiap upaya yang diselenggarakan secara bersama-sama dalam suatu organisasi untuk memelihara dan meningkatkan derajat kesehatan, mencegah dan mengobati penyakit serta memulihkan kesehatan perorangan, kelompok, keluarga, dan maupun masyarakat (Supriyanto S, 2010).

Salah satu indikator untuk menilai bagaimana pemanfaatan puskesmas sebagai Pusat pelayanan kesehatan oleh masyarakat adalah dari banyak atau tidaknya jumlah kunjungan ke Puskesmas tersebut. Rendahnya kunjungan masyarakat ke Pusat Pelayanan kesehatan menunjukan bahwa kurang memanfaatkan Pelayanan kesehatan Puskesmas (Wahyuni, 2012).

Pemanfaatan pelayanan kesehatan di Puskesmas Dempar dari hasil penelitian ini menujukan dalam 3 bulan terakhir sebagai besar masyarakat Kecamatan Nyuatan memanfaatkan pelayanan kesehatan di Puskesmas yaitu sebanyak 264 (88.3\%) responden memanfaatkan pelayanan kesehatan di Puskesmas. 


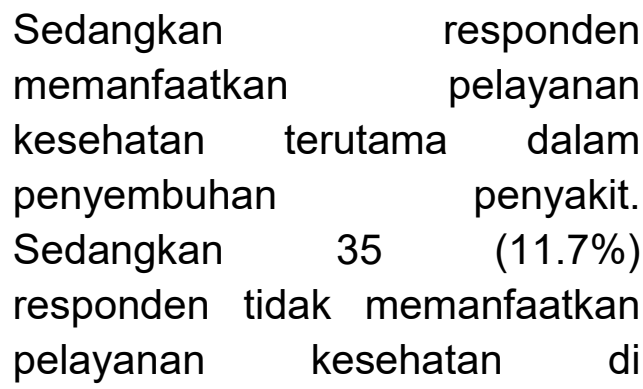

Puskesmas Dempar, dikarenakan responden mencari pengobatan ke alternatif pelayanan kesehatan yang lain seperti rumah sakit ataupun klinik serta melakukan upaya penyembuhan sendiri dengan mengkonsumsi obat warung, pemanfaatan tumbuhan lokal, dan upacara belian. Kenyataan lain yang dapat tergali dari penelitian ini adalah masyarakat ternyata tidak hanya mengunjungi puskesmas saja dalam mencari upaya pelayanan kesehatan dalam 3 bulan terakhir tetapi juga mengunjungi pusat pelayanan kesehatan lain seperti rumah sakit dan bidan praktek yang berada diluar wilayah Kecamatan Nyuatan. Kenyataan ini menujukan bahwa ada hal lain yang kurang mendukung dari Puskesmas yaitu jam pelayanan Puskesmas yang terbatas dari jam 09.00 hingga jam 12.00 siang.

\section{Hubungan Struktur Sosial dengan Pemanfaatan Pelayanan Kesehatan di Puskemas Dempar} Menurut Soenjono Soekanto 2002, pengertian struktur sosial dapat didefinisikan sebagai suatu tatanan sosial dalam kehidupan masyarakat yang ada didalamnya terkandung hubungan timbal balik antara status dan peran dengan batas-batas perangkat unsurunsur sosial yang merujuk pada suatu keteraturan perilaku, sehingga dapat memberi bentuk sebagai suatu masyarakat.

Struktur sosial erat kaitannya dengan kebudayaan salah satunya meliputi kebudayaan dalam pemilihan pengobatan. Sumber pengobatan di dunia mencakup tiga sektor yang saling terkait yaitu pengobatan rumah tangga atau pengobatan sendiri, pengobatan tradisional dan pengobatan medis yang dilakukan oleh perawat, dokter, Puskesmas atau Rumah Sakit (Rahayu, 2012).

Kemudian menurut Anderson dalam Notoatmodjo (2010) dengan sistem model kesehatan (health system model), percaya bahwa setiap individu mempunyai perbedaan karakteristik, mempunyai perbedaan tipe dan frekuensi penyakit, mempunyai perbedaan pola pengobatan dan penggunaan pelayanan kesehatannya masing-masing. la menambahkan bahwa struktur sosial, gaya hidup pada akhirnya mempengaruhi perbedaan pola penggunaan pelayanan kesehatan. 
Dalam penelitian ini hasil yang diperoleh berdasarkan uji statistik dengan didapatkan nilai $(P$ Value $0,497>\alpha 0,05)$ dapat disimpulkan bahwa tidak ada hubungan antara struktur sosial dengan pemanfaatan pelayanan kesehatan. Responden memilih struktur sosial hanya 13 atau $(4.3 \%)$ menggunakan alternatif pengobatan lain yang tersebar di 7 kampung wilayah peneliitan. Alternatif pengobatan yang digunakan seperti pengobatan tradisional ritual belian, nyegok, betawar, serta ramuan-ramuan dengan memanfaatkan tumbuhan lokal, seperti kulit langsat kulit pohon kemiri, yang untuk membantu menyembuhkan penyakit tifus, kumis kucing dan rumput buncar yang berkhasiat untuk membantu penyembuhan penyakit batu ginjal dan tuberculosis, daun sirsak, kasa bling, daun klorofil yang dapat membantu meredakan penyakit hipertensi atau tekanan serta jahe, kunyit, daun klorofil, daun binahong dan tumbuhan lokal lainnya yang di anggap berkhasiat dalam upaya penyembuhan penyakit.

\section{Berdasarkan}

hasil

penelitian, responden yang memilih untuk melakukan pengobatan tradisional lebih banyak dari kelompok umur dewasa akhir dan lansia alasan para responden menggunakan pengobatan tersebut adalah karena sudah terbiasa dengan metode pengobatan yang sudah menjadi tradisi masyarakat setempat. Namun bukan berarti responden tersebut tidak pecaya dengan pelayanan kesehatan hanya saja pengobatan tersebut merupakan salah satu cara yang dipercayai masyarakat untuk mendapatkan kesembuhan jika penyakit sudah tidak dapat ditangani oleh pihak puskesmas atau rumah sakit.

Hasil Penelitian ini berbeda dengan hasil penelitian Rahayu tahun 2012, persentase responden yang memilih pengobatan tradisional melalui sikerei lebih tinggi pada golongan responden yang kebudayaan masih tradisional $(88,1 \%)$ dibandingkan dengan responden yang telah modern (6,9\%). Terdapat hubungan bermakna antara kebudayaan dengan pemilihan pengobatan responden $(p=0,000)$. .Berdasarkan data yang ditemukan, menguatkan bahwa penelitian ini berbeda dengan penelitian Rahayu (2012), hasil penulisan ini menujukan masyarakat sebagain masyarakat sudah mulai mengurangi kegiatan pengobatan tradisional yang magis dan lebih banyak responden yang memilih untuk berobat ke layanan kesehatan. Alasan lain masyarakat tidak menggunakan 
pengobatan tradisional ritual belian yaitu dari segi tenaga dan biaya yang lebih besar dibandingkan ke pelayanan kesehatan. Jika, menggunakan pengobatan tradisional, minimal biaya yang dikeluarkan minimal 1 juta belum disertai dengan perlengkapan lainnya.

\section{Hubungan Kepercayaan \\ Kesehatan \\ Pemanfaatan \\ Kesehatan di \\ Dempar}

Kepercayaan kesehatan adalah sebuah bentuk perilaku dimana seseorang memberikan penilaian dan penjabaran terhadap kesehatan dari segi sosio-psikologis. Sedangkan perilaku merupakan kumpulan berbagai faktor yang saling berinteraksi. Sering tidak disadari bahwa interaksi tersebut amat kompleks sehingga kadangkadang seseorang tidak sempat memikirkan penyebab menerapkan perilaku tertentu (Maulana, 2009).

Hasil penelitian ini diperoleh bahwa hubungan antara kepercayaan dengan pemanfaatan pelayanan kesehatan sebanyak 95 (31.8\%) responden yang memiliki tingkat kepercayaan tinggi terhadap pelayanan kesehatan di puskesmas dempar, sedangkan $23(7.7 \%)$ responden memiliki tingkat kepercayaan yang rendah terhadap pelayanan kesehatan. $\mathrm{Hal}$ ini dipengaruhi oleh beberapa faktor yakni pelayanan yang diberikan oleh petugas kurang baik, petugas kesehatan dibeberapa puskesmas pembantu (pustu) yang tidak berada di tempat pelayanan, sehingga sebagian besar memilih untuk menggunakan warung, atau mengunakan tanaman obat yang dipercaya secara turun temurun untuk mengatasi penyakit. Selain itu ada beberapa responden yang mengatakan obat yang diberikan kurang ampuh dalam menyembuhkan penyakit sehingga beberapa responden tersebut lebih memilih untuk berobat ke rumah sakit dibandingkan ke puskesmas sehingga, bukan hanya faktor dari individu itu sendiri saja yang dapat mempengaruhi pemanfaatan pelayanan kesehatan, melainkan faktor dari eksternal dalam hal ini perilaku petugas kesehatan dalam melayani pasien juga menjadi salah satu faktor yang dapat mempengaruhi pemanfaatan seseorang terhadap pelayanan kesehatan dalam hal ini puskesmas.

Hasil penelitian ini sejalan dengan teorinya Anderson dalam Notoatmodjo (2010) dengan model sistem kesehatan (health system model), pecaya bahwa 
setiap individu mempercayai adanya kemanjuran dalam penggunaan pelayanan kesehatan. Dalam teorinya itu pun tersebut ia mengatakan bahwa faktor-faktor predisposisi dan faktor yang memungkinkan untuk mencari pengobatan dapat terwujud dalam tindakan apablia itu dirasakan sebagai kebutuhan.

Dari hasil wawancara dengan beberapa responden menyatakan bahwa setuju jika kondisi tumbuh sedang tidak sehat akan mengalami penurunan dan apabila terdapat anggota keluarga yang sakit sesegera mungkin untuk mencari upaya penyembuhan dengan mengobati sendiri terlebih dahulu dengan obat-obatan yang tersedia di rumah namun jika setelah 3 hari tidak mengalami perubahan maka responden tersebut mengambil tindakan upaya lanjut ke pusat pelayanan kesehatan ataupun rumah sakit.

Pelayanan puskesmas yang diberikan dalam upaya membantu penyembuhan penyakit dicakupan wilayahnya sudah cukup tinggi, hal ini ditunjukan dengan kepercayaan masyarakat yang mengutamakan untuk ditangani oleh tenaga kesehatan. Hasil penelitian ini didukung oleh penelitian yang dilakukan Alimudin A dkk, 2017 menyatakan bahwa variabel kepercayaan terhadap nilai dan kepuasaan pelanggan di Rumah Sakit Bedah Surabaya memiliki pengaruh yang signifikan dimana semakin tinggi tingkat kepercayaan pelanggan pada Rumah Sakit, semakin berpengaruh terhadap nilai dan kepuasaaan pelanggan dan sebaliknya.

Berdasarkan data hasil penelitian menyatakan bahwa kepercayaan kesehatan merupakan salah satu faktor yang mempengaruhi pemanfaatan pelayanan kesehatan di puskesmas Dempar. Dimana $P$ value yang diperoleh adalah 0,844 yang lebih besar dari $\alpha=0,05$ sehingga dapat disimpulkan variabel kepercayaan kesehatan tidak ada hubungan dengan pemanfaaan pelayanan kesehatan, terdapat $95(31.8 \%)$ responden memiliki tinggi terhadap pelayanan kesehatan.

4. Hubungan

Penilaian

Kesehatan dengan

Pemanfaatan

Pelayanan

Kesehatan di Puskemas

Dempar

Penilaian kesehatan menurut (Littik, 2008) dapat diukur dari gangguan kesehatan atau kesakitan yang dikeluhkan sendiri oleh individu yang bersangkutan. Status kesehatan merupakan ukuran yang memadai untuk mengukur 
kebutuhan kesehatan atau pemanfaatan ke pelayanan kesehatan. Kebutuhan terhadap pelayanan kesehatan dapat diukur menggunakan penilaian kesehatan individu.

Berdasarkan hasil penelitian ini dan hasil uji dari analisis hubungan antara penilian kesehatan dengan pemanfaatan pelayanan kesehatan di Puskesmas Dempar memperlihatkan bahwa terdapat 121 (40.5\%) responden memiliki penilaian kesehatan yang baik terhadap keadaan dirinya menurut keadaan sakit yang dirasakan sedangkan 28 (9.4\%) responden lainnya memiliki penilaian kesehatan yang kurang baik atau buruk terhadap keadaan dirinya.

Menurut Supriyanto (2010) menyatakan bahwa suatu tingkat kebutuhan terhadap pelayanan kesehatan sama dengan keadaan sehat sakit seseorang yang dinyatakan dalam angka kesakitan, kematian dan disabilitas. Diperkuat juga melalui teori Andersen

menjelaskan bahwa salah satu faktor pemanfaatan pelayanan kesehatan adalah karakteristik kebutuhan (need characteristic). Faktor status kesehatan, risiko sakit dan lingkungan mempunyai hubungan yang erat terhadap perilaku penggunaan pelayanan kesehatan.
Setiap orang pasti mempunyai penilaian berbedaberbeda terkait dengan kondisi kesehatannya, begitu pula hasil yang didapatkan pada penelitian ini masing-masing responden memberi penilaian terhadap keadaan dirinya menurut keadaan sakit yang ia rasakan serta pendapat responden akan kebutuhan atau tindakan untuk segera mendapatkan pelayanan kesehatan apabila merasa sakit. Sehingga jika responden memiliki penilaian kesehatan yang baik maka ia akan selalu memanfaatkan pelayanan kesehatan dan tidak menunggu sakitnya parah untuk segera melakukan pencarian pelayanan kesehatan.

Hasil ini sejalan dengan toeri yang ada dalam buku Notoatmodjo (2010) yang menyatakan bahwa masalah kesehatan (penyakit) dalam masyarakat, akan dipersepsikan berbeda-beda oleh masingmasing orang. Bahkan beberapa orang yang menderita penyakit yang sama, pada sebagaian orang dipersepsi sebagai penyakit, tetapi bagi sebagaian lain dipersepsikan bukan sebagai penyakit.

Kebutuhan masyarakat terhadap pengobatan umumnya dikaitkan dengan kondisi sakit yang menganggu aktivitas responden, namun berbeda 
dengan hasil penelitian ini ada sebagian responden memiliki penilaian yang kurang baik atau buruk terhadap keadaan dirinya, akan terus melakukan aktivitas walaupun keadaan tubuh sedang tidak sehat, menunda kebutuhan untuk mendapatkan pelayanan kesehatan, sehingga biasanya berusaha untuk mengobati diri sendiri dengan membeli obat warung, dan ada sebagaian menggunakan obat tradisional dengan tumbuhan lokal yang ada seperti kulit langsat, kulit pohon kemiri, yang untuk membantu menyembuhkan penyakit tifus serta kumis kucing dan rumput buncar yang berkhasiat untuk membantu penyembuhan penyakit batu ginjal, selanjutnya daun sirsak, kasa bling, daun klorofil yang dapat membantu meredakan penyakit hipertensi serta masih banyak obat-obatan lainnya upaya tersebut dilakukan oleh responden.

Hasil penelitian ini sejalan dengan penelitian yang dilakukan oleh Handayani dkk (2003) menyatakan bahwa aktivitas pada penduduk sakit dengan upaya pencarian pertolongan pengobatan maka dapat dilihat bahwa ada kecenderungan yang sama untuk melakukan pengobatan sendiri baik pada penduduk sakit dengan atau tanpa gangguan aktivitas.
Penilaian masyarakat tentang kesehatan masih belum sesuai dengan konsep sehat sakit yang sebenarnya. Responden merasa dirinya sakit ketika kondisi tubuh dapat lagi menjalankan aktivitas serta masyarakat yang tidak berobat ke puskesmas dikarenakan responden tersebut merasa tidak sembuh bila berobat di Puskesmas, selain itu adanya pandangan bahwa responden tidak yakin apabila penyakitnya diobati di Puskesmas.

Hasil dari penelitian menyatakan bahwa penilian kesehatan merupakan salah satu faktor yang mempengaruhi pemanfaatan pelayanan kesehatan di puskesmas Dempar. Dimana hasil uji menunjukkan $p$ value yang diperoleh adalah 0,004 yang lebih kecil dari $\alpha=0,05$ maka $\mathrm{H} 0$ pada penelitian ini ditolak, artinya ada hubungan antara penilaian kesehatan.

Implikasi dari penelitian ini, adalah naik turunnya pemanfaatan pelayanan kesehatan di Puskesmas. Dipengaruhi oleh penilaian kesehatan masyarakat maka agar pemanfaatan pelayanan kesehatan meningkat penilaian kesehatan harus diperbaiki dan di tingkat.

Menurut penelitian Alimudin dkk 2017, untuk meningkatkan 
penilaian kesehatan masyarakat terhadap pelayanan kesehatan yaitu dengan memberikan program pengembangan sumber daya manusia secara terus menerus kepada dokter dan perawat sehingga dapat meminimalkan kesalahan dalam memberikan pelayanan kepada pasien. Kemudian meningkatkan awareness petugas kesehatan kepada pasien, sehingga tindakan yang dilakukan dan pelayanan yang diberikan menjadi lebih cepat dan tepat. Selanjutnya memberikan pelayanan kepada pasien seperti melayani keluarga sendiri sehingga kondisi ini dapat menimbulkan perasaan yakin dan terjamin bila pasien berobat.

\section{KESIMPULAN}

Hasil penelitian menujukan terdapat hubungan antara peniaian kesehatan dengan pemanfaatan pelayanan di Puskesmas Dempar Kecamatan Nyuatan Kabupaten Kutai Barat. Responden memiliki tingkat kesadaran yang baik terhadap kondisi kesehatan, memilih untuk tidak beraktivitas berat ketika kondisi tubuh sedang sakit ataupun secepat mungkin mencari cara untuk memulihkan kondisi

\section{DAFTAR PUSTAKA}

Alimudin A, Dhaniarti I, Jadana L.M, Sukoco A. "Model of Customer Value Approach for Improving Satisfaction of the Hospital Patients." Sinergi 2017 ; 7.2. Jurnal IImiah IImu Manajemen. http://ejournal.unitomo.ac.i d/index.php/feb/article/dow nload/365/222

Data. Profil Kesehatan Puskesmas Dempar. 2017.

Data. Pusat Kesehatan Masyarakat RI per akhir Desember. 2017

Handayani L, Siawanto, Ma'ruf NA, Hapsari D, 2003. Pola Pencarian Pengobatan di Indonesia (Analisis Data Susenas 2001). Puslitbang Pelayanan dan Teknologi Kesehatan, Badan Litbangkes. Jakarta.

Kemenkes, RI. 2014. Peraturan Menteri Kesehatan RI Nomor 75 Tahun 2014 tentang Pusat Kesehatan Masyarakat. Indonesia : Kemenkes RI.

Maulana, Heri, D.J., 2009. Promosi Kesehatan. Jakarta : EGC

Napirah, Muh. Ryman; Rahman, Abd.; Tony, Agustina (2016). Faktor-faktor yang berhubungan dengan pemanfaatan pelayanan kesehatan di WIlayah Kerja 
Puskesmas Tambarana

Kecamatan Poso Pesisir

Utara Kabupaten Poso. Jurnal Pengembangan Kota.

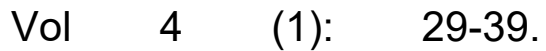
https://ejournal2.undip.ac.id/ index.php/jpk/article/view/58 5.

Notoatmodjo, S. (2010). IImu perilaku kesehatan. Jakarta; Rineka Cipta.

Rahayu, A. D (2012). Faktor Faktor yang Berhubungan dengan Pemilihan Pengobatan Tradisional di Wilayah Kerja Puskesmas Muara Siberut Kecamatan Siberut Selatan Kabupaten Kepulauan Mentawai Tahun 2012. 38 (1989-2012). http://repository.unand.ac.id/ 20158/1/jurnal.pdf

Supriyanto. 2010. Pemasaran Industri Jasa Pelayanan Kesehatan. Yogyakarta: CV Andi Offset.

Wahyuni, S.N. 2012. "FaktorFaktor yang Berhubungan dengan Pemanfaatan Pelayanan Kesehatan di Puskesmas Sumber Rejo Kota Balikpapan Provinsi Kalimantan Timur Tahun 2012". Skripsi. Fakultas Kesehatan Masyarakat. Universitas Indonesia : Depok, Jawa Barat. lib.ui.ac.id/file?file=digital/20 320041-S-Nanik Sri
Wahyuni.pdf [Diakses pada tanggal 21 Mei 2018] Wulandari, Ahmad, Saptaputra. (2016). Faktor Yang Berhubungan Dengan Pemanfaatan Pelayanan Kesehatan Di Uptd Puskesmas Langara Kecamatan Wawonii Barat Kabupaten Konawe Kepulauan Tahun 2016. https://media.neliti.com/medi a/publications/183311-IDfaktor-yang-berhubungandengan-pemanfaat.pdf 